\title{
Discovering Successful Second Language Teaching Strategies and Practices: From Programme Evaluation to Classroom Experimentation
}

\begin{abstract}
A Response
Robert Keith Johnson

Department of Education, The University of Hong Kong, Pokfulam Road, Hong Kong
\end{abstract}

The cycle of discovery that Swain describes moves from evaluation to theory building and the generation of hypotheses to experimentation and further evaluation. It is a recursive process and one which, as she shows, has been highly productive in the context of Canadian immersion programmes. The initial concern of researchers in Canada was to determine whether under appropriate conditions immersion can work; i.e. that first language (L1) development and educational achievement are not impaired by using a second language (L2) as medium of instruction and that a high level of L2 proficiency can be added to normal L1 development. The research showed that the L2 proficiency acquired is not fully equivalent to that of a native speaker but is a major advance on levels of L2 proficiency achieved through teaching the target language as a subject. This outcome, additive bilingualism, was shown to be achieved in literally hundreds of programme evaluations. The consistent results in these replications, which is essentially what they were, were used to support a coherent body of theory, allowing researchers to focus upon the effects of different types of immersion (early/late; full/partial) and areas of relative weakness in immersion outcomes, in particular the differences in immersion students' performance between receptive and productive language skills and the marked and consistent difference between the grammatical control of immersion students (or rather the lack of it) and that of comparable native speakers. In order to investigate this phenomenon, to develop further the theoretical model and to devise practical means for overcoming as well as understanding identified weaknesses in their immersion programmes, the focus in research in Canada has moved from product to process. Swain presents the findings of this process-oriented research under the headings Input, Instruction (Grammatical Instruction, Vocabulary Instruction, Error Correction) and Output.

In this discussion I want to use Swain's summary of Canadian research on immersion to raise as a question the extent to which bilingual education theory and the practices derived from it are universal or context specific; or to put it another way, to question the extent to which learning outcomes predicted by the Canadian experience are likely to change, and how, as contextual factors vary. I want to argue, and I believe this is what Swain is saying too, that what needs to be transferred to other bilingual education contexts is not a 'Canadian model' of 
immersion, but the 'cycle of discovery' and the progression from the evaluation of product to process. This research agenda can be applied in any context to show what the product is, why the product is achieved, and what changes are required to bring aims and achievement into line. It may involve the adjustment of aims or processes or both.

The general interest of such research increases the greater the differences between the educational context in which the programme is being developed and other contexts where extensive research has already been carried out. Bilingual education is therefore one of the few research areas where developing countries and education systems can and should play an important, even leading role. In terms of theory, research under a variety of conditions will help to show to what extent a unitary theory of bilingual education may be possible and useful. In terms of practice, evaluation should help (to take an extreme view) to prevent educational disasters or, at the other extreme, to facilitate the fine-tuning that every education programme should receive and can benefit from.

Before discussing some of the variables that I feel may have major implications for the processes and products of bilingual education, I should perhaps declare my position. This is that bilingual education, involving the use of a second language (or third or fourth) as medium of instruction, is a high risk undertaking. Canadian and other research has shown that the gains can be considerable, not only in terms of additive bilingualism but in cognitive advantage too. Where circumstances are less favourable, I believe the costs can be equally great. There is a danger in the demonstrated success of French immersion in Canada that outcomes may be attributed solely to features of the programmes, or even more crudely to L2 instruction itself, rather than to a more complex interaction involving the educational, sociolinguistic, economic and political environment in which the programmes were carried out.

In this review of some effects of contextual variation, I will focus primarily on potential costs and their causes and I will begin by defining two types of outcome other than additive bilingualism, which may result from using an L2 as medium of instruction. The first is 'replacive' bilingualism, also referred to as 'subtractive' bilingualism in the literature, whereby L2 proficiency is gained at the expense of the L1; i.e. the L2 replaces the L1 as the language in which cognitive academic skills are developed, maintained and applied. In some contexts and for many students, replacive bilingualism is the only option. There is no L1 medium education on offer. Papua New Guinea, where I worked for nine years, is an extreme but not unique example. Over 850 languages have been identified, with an average of 4500 speakers per language. Approximately half have less than 1000 speakers and considerably more have no written form. The Melanesian region as a whole has one tenth of one percent of the world's population, but nearly a quarter of the worlds' languages are spoken there (Smith, 1995). For the great majority of Melanesians, multilingualism is a way of life, but formal education is only possible through a second language (English, French, a local language which happens to have a written form, or a lingua franca such as Melanesian Pidgin or Bislama). Even when L1 literacy can be attained, the literature available in that language is limited and the opportunities for extended or higher level education through that medium, non-existent. 
Other causes of replacive bilingualism exist, for example where imperialist or nationalist forces impose an L2 medium and deny or limit students' opportunities for L1 academic development and maintenance, or where parents reject the L1 in favour of an L2 which offers their children greater opportunities for academic, political or social advancement, or where the children themselves reject their mother tongue in favour of the L2, as has happened in various immigrant communities in the past. My point here, an obvious one perhaps, is that none of these examples, each of which is subject to still further contextual variation, is comparable with immersion. Additive bilingualism is not the aim and the roles and status of the L1 and the L2 are radically different from the Canadian context and experience, at least so far as French immersion is concerned. Theory and practice derived from the Canadian experience would need to be applied with the utmost caution in such very different situations, never uncritically and never without monitoring and evaluation.

I referred earlier to two types of bilingual outcomes of L2 medium programmes other than additive bilingualism. For the third kind I will use the clumsy, but at least transparent terms 'academic semi-lingualism' and 'academic semi-bilingualism'. These outcomes differ from the controversial term semi-lingualism in that no claim is made regarding social communication. Academic semi-lingualism occurs where no education is offered in the L1, but the L2 is not acquired to a level (i.e. the L2 threshold level Swain refers to) which would permit the student to engage effectively with the L2 curriculum. Academic semi-bilingualism is similar except that the L1 is or has been a medium of education but is not adequately maintained. L2 medium education is provided, in each of these types of programmes, but neither additive nor replacive bilingualism is achieved because the students in question are unable to engage effectively with the L2 curriculum. The L2 is not mastered adequately and the students' education through the L2 suffers as a result. The opportunity for educational development through transfer from the L2 to L1 is also restricted, first because little is learned through the L2 that could be transferred and second because opportunities for transfer are limited or non-existent.

\section{Factors Affecting Product and Process in Bilingual Education}

I thought it might be appropriate here to focus on some more specific features which distinguish the Canadian immersion context from other bilingual education contexts and consider how these differences may affect the outcomes and processes of those programmes.

\section{L2 medium curriculum}

The curriculum followed by French immersion students in Canada differs from the L1 English curriculum only in the medium. This fact presumably contributes to the ability of those immersion students to perform as well on tests of subject knowledge as their L1 medium peers; i.e. what they are tested on is what they have learned. If the L2 medium curriculum differed from that of the L1, the performance of the L2 medium students would presumably be affected as a consequence and in proportion to the extent of the difference. There is of course no reason why the L2 medium curriculum should follow the L1 
curriculum, and L2 medium students should be tested on what they havelearned rather than what they have not. My point is that where the L1 and the L2 curricula differ, a factor enters the bilingual educational equation which is not present in the Canadian context.

\section{The L1 environment of bilingual education}

In Canada the status of L1 English is secure and the language is used to perform the full range of communicative functions, spoken and written. This fact must contribute in important ways to the success of French immersion students in maintaining their development in the L1. It seems likely in fact that this social factor may be more important than any provision for L1 maintenance within the curriculum and that different L1 social environments may result in very different effects on the L1 development of L2 medium students, regardless of the provision made within the curriculum for L1 maintenance.

\section{The $\mathbf{L}$ environment of bilingual education}

One feature which distinguishes French immersion in Canada from many other bilingual education programmes is the lack of opportunities for students to communicate in the target language outside the classroom. Baetens Beardsmore \& Swain (1985) compared French L2 medium programmes in Canada where there was limited or no exposure to the target language outside the classroom, with programmes in Brussels where such opportunities were readily available. The students in Brussels achieved a level of L2 French proficiency equivalent to that of the Canadian students in approximately half the time. What is required is further research into the effects of different types and degrees of exposure to the L2 outside the classroom so that bilingual educators can have a better understanding of the ways in which the L2 environment can be exploited most effectively.

On linguistic environment in general, what happens outside the classroom seems to be as important or more so in accounting for differences in levels of L2 achievement (and L1) than what happens inside it.

\section{The linguistic homogeneity of students}

A feature of Canadian immersion programmes, is the degree of linguistic homogeneity of the students. They have (in general) the same L1 and similar levels of L2 proficiency on entry to the programme. Early immersion students are assumed to have little or no French, while in mid- and late immersion students are assumed to have a similar background in core French with (broadly) similar outcomes. This relative homogeneity has implications for the programmes and, presumably, their outcomes. It is easier to plan and implement a curriculum under these circumstances and to develop materials and teaching and learning strategies which are appropriate for the students.

The situation is very different where for example students speak a variety of different first languages. This makes L1 maintenance more difficult or even impossible, but creates an environment in which the target language becomes the social as well as the academic lingua franca of the group, with resultant gains in motivation to use that language and a broadening of the range of functions for 
which it is used. The Canadian context is also very different from those in which bilingual education programmes cater for L1 as well as L2 speakers of the target language(s) or have L2 speakers with widely varying initial levels of proficiency. As with the other factors considered here, outcomes achieved in these different situations are likely to suffer if inappropriate assumptions are made, while success will depend upon how effectively the constraints of the particular context are dealt with and the opportunities presented by that context are exploited.

\section{The teachers' language proficiency}

The teachers in Canadian immersion programmes are bilingual, fluent in the students' L1 and the target L2. In other contexts the teachers may speak the L1 of some students but not others, or they may be monolingual speakers of the target language. In either case the ability of students and teachers to maintain communication is limited to the students' weaker language. This has a cost in terms of the students' ability to use their L1 to communicate with the teacher, but a potential gain in terms of their motivation to become proficient in the L2.

There is also wide variation across programmes and contexts in the type and level of bilingual proficiency of teachers. In Canada the level is likely to be consistently high. Where the general levels of L2 proficiency of teachers is low the effects on outcomes must be great, and where the use of the L2 as medium involves large numbers of students and teachers, the time needed to raise the proficiency of teachers in all subjects affected may be considerable, particularly where the economic benefits to be gained from high levels of bilingual proficiency are greater outside than inside the teaching profession. The types of proficiency teachers control must also affect outcomes. Training may again have only limited and long term benefits. As an example, in a context where the L2 is not used outside the classroom, a teacher whose proficiency is limited to formal and academic functions will not develop sociolinguistic competence from further classroom instruction. In addition, classroom instruction by instructors who themselves lack sociolinguistic competence may be all that is available.

These may be examples of situations where it is more sensible to limit the aims of the programmes and succeed in what can be achieved rather than failing in what cannot. Research into the effects of different levels and types of bilingual proficiency in teachers would in any case be valuable, but may be difficult to conduct. Attempts have recently been made in Hong Kong to define levels of L2 proficiency required for the certification of teachers of second languages and L2 medium content subject teachers. The concept is, not surprisingly, proving sensitive as well as difficult to operationalise.

\section{Choice of medium of instruction}

In Canada no parent has to select and no student has to study through French immersion unless they choose to do so. Similarly all, or almost all the teachers, school principals, teacher-trainers, curriculum advisors and administrators involved in immersion are there because they want to be. The mainstream L1 curriculum is available and by taking the L1 option no disadvantage is incurred. We may therefore assume a very high level of commitment and motivation across immersion programmes in Canada from all those involved, and a high level of 
motivation and commitment is often enough in itself to guarantee good results when a 'special' programme is compared with the normal population. Where there is no L1 option, however, or where the L1 option is perceived to be (and often is) inferior in the curriculum it offers, the academic and career opportunities it affords, and its status within the community, the motivation of those involved may be very mixed and the levels of commitment more varied. A low level of motivation and of commitment is most likely where, as in many developing economies, the provision of education has outstripped the capacity to provide jobs. In many such situations, an L2 has little or no value for students unless they can enter paid employment of some kind.

\section{Features that Differentiate amongst Immersion Programmes}

It is perhaps obvious that experience derived from immersion programmes needs to be applied cautiously to other bilingual education contexts. Even within immersion, however, i.e. amongst programmes which are similar in many ways to Canadian French immersion, there are still many possible variations and these variations can affect both the processes by which outcomes are achieved and the product itself. I will use Hong Kong, the situation I am most familiar with, to illustrate some of these differences.

\section{Selection for mid- and late immersion}

In different contexts the effects of early, mid or late immersion may vary, and require different approaches to implementation. In Canada, neither replacive bilingualism nor academic semi-bilingualism appear to be a problem and there has been no pressure to restrict entry into L2 medium programmes to those who meet specific prerequisites or to exclude those for whom there may be adverse consequences educationally or linguistically. In Hong Kong, the danger of academic semi-bilingualism is widely recognised. It is considered to exist for a considerable though ill-defined proportion of students entering the almost universal late immersion programme which has developed there. Measures are now being introduced which seek to restrict entry to the programme to students who have shown high levels of L1 Chinese development and general academic ability at primary level and who meet a minimum requirement in L2 English. Selection has been widely condemned by parents and many in the community as elitist and as discrimination against those who would be 'forced' to continue Chinese medium education. Since the government is unlikely to take a hard line on such a divisive and controversial issue, semi-bilingualism is likely to continue to be a problem amongst less able students.

\section{Differences between L1 and L2 languages and writing systems}

In Canada, the two languages involved in the immersion programmes, French and English, are related. They share, particularly in academic and technical language, roots derived from Latin and Greek. Their writing systems are alphabetic, and cognate words, particularly in written form, are easily identified as such. Despite the danger of mistakes where commonality of meaning does not follow from similarity in form, the advantages of these commonalities considerably outweigh any disadvantages. 
In Hong Kong, the opposite is the case. Cantonese is a tone language, its phonology, morphology and syntax are very different from English, and the writing systems of the two languages are based on different principles. Even where cognates exist (e.g. through borrowing) they are difficult, if not impossible to identify as such, particularly in the written form. Part of the argument for selection for late immersion in Hong Kong is based on the premise that the task of changing the medium of instruction from spoken Cantonese and written Chinese to English, and subsequently of maintaining Chinese, is very much more difficult than it would be moving from English to French, or for that matter from Cantonese to Putonghua where the writing system is common to both languages.

\section{Demand for L2 medium instruction}

In Canada, the percentage of the student population entering immersion is small. In Hong Kong, motivation amongst parents for their children to acquire and eventually study through English is extremely high and the teaching of English often begins in pre-school and kindergarten, though English is very rarely used as a medium of instruction before secondary level and almost never for social communication amongst Cantonese speakers. Research is being conducted to establish how English can best be taught as a subject at primary level in preparation for the change in medium, the measures that can best be taken to assist students making the transition and measures that can be used to identify students at risk of semi-bilingualism.

\section{Extent of immersion}

In her review of Canadian research, Swain shows that partial immersion students achieve lower levels of L2 proficiency than those in full immersion. They also experience more difficulty in late immersion in particular in 'closing the L2 proficiency gap'; or achieving the L2 threshold level. In Hong Kong policy-makers have assumed that the differences between the languages and writing systems markedly increase the difficulty in closing that gap and therefore increase the costs of partial immersion relative to full immersion. As a result it is the policy that schools should have full (late) immersion in English from Grade 7 or no immersion at all with proportions approximately 30\% English immersion and $70 \%$ Chinese medium with English taught as a subject. Despite the policy, many schools have adopted various forms of partial immersion, and research is currently being conducted to monitor the effects.

\section{The use of the $\mathrm{Ll}$ by teachers}

Though practices vary in Canadian immersion classrooms, the general principle on the use of the L1 is well established. Students attempt to use the L2, but may use the L1 to avoid a breakdown in communication. Teachers, who must understand the students' L1, should nevertheless maintain the L2. In Hong Kong, this issue is as contentious as selection, and has received considerable attention from researchers investigating mixing and switching in the classroom and conducting attitude surveys. The conclusion of Education Commission Report No. 4 (1990), the most recent policy statement on language, was that 'mixed mode' teaching, (switching between English and Cantonese and the use of a 
mixed code, consisting of Cantonese discourse with English terminology inserted) should be reduced or eliminated. The extent of the problem can be illustrated by a recent survey which showed that Science and Mathematics teachers at 6th-Form level (G12 and 13) used mixed code as the dominant mode of instruction (over $60 \%$ of teacher-talk in each case). Only $10 \%$ of teacher-talk was in English, while the remainder was in Cantonese (Johnson et al., 1991).

\section{What Counts as Success in Bilingual Education}

In Canadian French immersion programmes, parents and students want first to be assured that linguistic and educational development in the L1 will not suffer. The great majority of these students will go to English not French medium tertiary institutions and their competence in L1 English will be a more important factor in their future careers than L2 French. Some, perhaps a majority may never use French professionally at all, and even social and cultural use of the language may be limited.

In many parts of the world, certainly in Hong Kong and much of Southeast Asia, a high level of education and proficiency in L2 English is the key to upward and in the case of Hong Kong also outward mobility. A recent study of the expectations of the Hong Kong community regarding levels of language proficiency (Johnson \& Cheung, 1992) showed that community expectations with regard to English, for 'High Level Literates' were higher than those for Chinese. This is not surprising, given that a high level of proficiency in English is essential to reach the highest levels in education, the professions or business, but it makes the task of meeting these expectations difficult or impossible.

Canadian researchers are clearly not complacent about the levels of L2 French achieved through immersion, but the Anglophone community in general (in so far as it cares) seems well enough satisfied. In Hong Kong, no issue in education has received more public attention, or government money, than efforts to improve the standard of L2 English which is universally perceived to be falling. All the evidence is to the contrary, that the level of general proficiency in English has risen dramatically. The problem has been the failure of supply to match the quantitative and qualitative rise in demand as Hong Kong has changed from a low cost manufacturing centre to the centre of business and finance for the fastest growing economic region in the world.

\section{Summary and Conclusion}

Swain has presented a number of cultural and political aspirations in Canada that led to the French immersion programmes, and which have been researched more intensively than perhaps any other language education initiative. I have argued that the aims, implementation and outcomes of Canadian immersion programmes are in many ways unique to that context. However, the example of the role research can play in programme development and evaluation, the cycle of discovery, is one that every bilingual education programme should adopt. Apart from its practical value for the programmes concerned, such research should also contribute to the development of bilingual education theory, provided effective means can be found for sharing and comparing results. It should be possible to establish principles which if applied under ideal conditions 
produce optimal results. Perhaps, through the work of Swain and other researchers, we already have these principles. If so, comparative research of this kind will still be important, since it will enable us to understand better and predict the effects of contextual variables and pragmatic constraints on the operation of those principles in practice and upon programme outcomes.

\section{References}

Baetens Beardsmore, H. and Swain, M. (1985) Designing bilingual education: Aspects of immersion and 'European School' models. Journal of Multilingual and Multicultural Development 6 (1), 1-15.

Education Commission (1990) Education Commission Report No.4. Hong Kong: Hong Kong Government Printer.

Johnson, R.K. and Cheung, Y.S. (1992) Reading literacy in Hong Kong in Chinese and English: A preliminary report on the IEA study. In N. Bird and J. Harris (eds) QUILT AND QUILL: Achieving and Maintaining Quality in Language Teaching and Learning (pp. 408-19). Hong Kong: Institute of Language in Education.

Johnson, R.K., Shek, C.K.W. and Law, E.H.F. (1991)Implementing Hong Kong's proposed language policy for secondary schools: Research and its implications. In N. Crawford and E.K.P. Hui (eds) The Curriculum and Behaviour Problems in Schools: A Response to Education Commission Report No. 4 (pp. 95-109) (Faculty of Education Papers 11). Hong Kong: Hong Kong University).

Smith, G.P. (1995) Language choice in an acutely multilingual society: Communication and development in Papua New Guinea. Paper presented at the Second International Conference on Language in Development. Bali, Indonesia, 10-12th April, 1995. 